\title{
Microsphere Zirconomolybdate Sorbents \\ for Extraction of Lanthanides (III) \\ from Aqueous Solutions
}

\author{
Ekaterina A. Kutikhina*, \\ Elena V. Mazurova, Vladimir A. Parfenov, \\ Elena V. Fomenko and Tatiana A. Vereshchagina \\ Institute of Chemistry and Chemical Technology SB RAS \\ FRC "Krasnoyarsk Science Center SB RAS" \\ 50/24 Akademgorodok, Krasnoyarsk, 660036, Russia
}

\begin{abstract}
Micromesoporous zirconomolybdates with a specific surface area of $200 \mathrm{~m}^{2} / \mathrm{g}$ and pore sizes in the range of 10-40 $A$ ( $\left.D_{\max } \sim 15 \AA\right)$ were synthesized under hydrothermal conditions $\left(150{ }^{\circ} \mathrm{C}, 72 \mathrm{~h}\right)$. Microsphere composites were prepared by deposition of the zirconomolybdates on a microsphere hollow carrier with a macroporous shell $\left(D_{\text {pore }} \sim 2-10 \mu \mathrm{m}\right)$ resulted from the $\mathrm{NH}_{4} \mathrm{~F}-\mathrm{HCl}-\mathrm{H}_{2} \mathrm{O}$ etching of a cenosphere narrow fraction $(-0,08+0,071 \mathrm{~mm})$ separated from coal fly ash of Reftinskaya power station. The morphological type "cenospheres with a porous shell and a smooth surface" predominates in the fraction. The sorption properties of zirconomolybdates and microsphere composites with different $\mathrm{Mo} / \mathrm{Zr}$ ratio were studied regarding $\mathrm{Nd}^{3+}$ cations as a surrogate of trivalent actinides. It was established that the thin-layer mode of zirconomolybdate deposition on the carrier and the increasing of a Mo/Zr ratio in its composition provides the enhanced distribution coefficient (up to $10^{4} \mathrm{ml} / \mathrm{g}$ ) and efficiency of $\mathrm{Nd}^{3+}$ sorption (up to $85 \%$ ).
\end{abstract}

Keywords: sorbents, lanthanides, radioactive waste, zirconomolybdates, cenospheres.

DOI: $10.17516 / 1998-2836-0028$.

(C) Siberian Federal University. All rights reserved

* Corresponding author E-mail address: ekaterina_kutikhina@mail.ru 


\title{
Микросферические циркономолибдатные сорбенты
}

\section{для извлечения лантаноидов (III) из водных сред}

\author{
Е.А. Кутихина, Е.В. Мазурова, \\ В.А. Парфенов, Е.В. Фоменко, Т.А. Верещагина \\ Институт химии и химической технологии СО РАН \\ ФИЦ «Красноярский научный иентр СО РАН» \\ Россия, 660036, Красноярск, Академгородок, 50/24
}

Методом гидротермального синтеза (150 ${ }^{\circ} \mathrm{C}, \quad 72$ ч) получены микромезопористые ииркономолибдаты с удельной поверхностью около $200 \mathrm{M}^{2} / 2$ и размером пор в интервале $10-40 \AA$ $\left(D_{\max } \sim 15 \AA\right)$, а также микросферические композиции путем нанесения циикономолибдатов на микросферический полый носитель с макропористой оболочкой ( $\left.D_{\text {nор }} \sim 2-10 \mu \mathrm{m}\right)$. В качестве носителя использовали продукт травления $\mathrm{NH}_{4} \mathrm{~F}-\mathrm{HCl}-\mathrm{H}_{2} \mathrm{O}$ узкой фракции ценосфер (-0,08+0,071 мм) из летучей золь Рефтинской ГРЭС с преимущественным содержанием морфологического типа «ценосферы с пористой оболочкой и гладкой поверхностью». Изучень сорбиионные свойства ичикономолибдата и микросферических композиций с различным отношением $\mathrm{Mo} / \mathrm{Zr}$ в отношении катионов $\mathrm{Nd}^{3+}$ как имитатора трехвалентных актиноидов. Установлено, что тонкослойное нанесение циркономолибдата на носитель и увеличение отношения $\mathrm{Mo} / \mathrm{Zr}$ в его составе способствует повышению коэффициента распределения (до $10^{4}$ мл/2) и эффективности процесса сорбиии $\mathrm{Nd}^{3+}$ (до $85 \%$ ).

Ключевые слова: сорбенты, лантаноиды, радиоактивные отходы, чиркономолибдаты, ценосферы.

\section{Введение}

Поиск эффективных способов извлечения лантаноидов из водных сред важен как для повышения сырьевых запасов редкоземельных металлов, играющих ключевую роль в развитии высокотехнологичных отраслей промышленности $[1,2]$, так и для решения экологических проблем ядерного топливного цикла в связи с образованием жидких радиоактивных отходов (PAO), содержащих долгоживущие актиноиды (An) с периодом полураспада $10^{3}-10^{7}$ лет $\left({ }^{241,243} \mathrm{Am},{ }^{245,247} \mathrm{Cm},{ }^{239,240} \mathrm{Pu}\right.$ и др.). Благодаря сходству химических свойств лантаноидов и актиноидов, нерадиоактивные лантаноиды $\left(\mathrm{Ln}^{3+}\right)$ могут служить химическими аналогами актиноидов, в первую очередь, трехвалентных америция и кюрия, исследования с которыми затруднены ввиду их высокой токсичности и нестабильного состояния окисления в экспериментальных условиях [3, 4].

Конечной целью обращения с долгоживущими РАО служит их окончательная изоляция от биосферы в отвержденной минералоподобной форме путем захоронения в геологических формациях $[5,6]$. Разрабатываются различные способы включения актиноидов в структуру устойчивой твердой матрицы, среди которых весьма перспективными являются сорбционные 
способы иммобилизации с использованием радиационно-устойчивых неорганических сорбентов, специфичных в отношении определенных катионов металлов [7, 8]. К преимуществам сорбционных технологий относят возможность совмещения процесса извлечения радионуклидов из раствора РАО и их локализации в объеме сорбента, что позволяет без привлечения дополнительных реагентов осуществить перевод сорбированной формы радионуклидов в минералоподобную в ходе высокотемпературного фазового превращения сорбента.

Процессы получения кристаллических и стеклокристаллических форм РАО путем высокотемпературной обработки неорганических сорбентов, насыщенных катионами радионуклидов, являются предметом ряда исследований с использованием как селективных ионитов (вольфрамовые бронзы [9], силикотитанаты [10], цеолиты [11], молибдофосфаты [12], фосфаты [13] и др.), так и неселективных пористых материалов $[14,15]$. При этом большинство работ в этой области посвящено иммобилизации относительно более короткоживущих радионуклидов ${ }^{137} \mathrm{Cs}$ and ${ }^{90} \mathrm{Sr}\left(\tau_{1 / 2} \sim 30\right.$ лет) [9-12].

В перечень устойчивых минералоподобных фаз для иммобилизации актиноидов входят $\mathrm{Zr}$-содержащие фазы, включая цирконолит $\mathrm{ZrTi}_{2} \mathrm{O}_{7}$ и фазу NZP состава $\mathrm{NaZr}_{2}\left(\mathrm{PO}_{4}\right)_{3}$ [16-19]. В качестве сорбционно-активных прекурсоров этих фаз исследуются мезопористые цирконотитанаты [20] и гибридные цирконофосфонаты, получаемые путем функционализации поверхности мезопористого цирконата фосфорорганическими соединениями [21].

Ранее авторами $[22,23]$ продемонстрирована перспективность использования слоистого циркономолибдата $\mathrm{Zr}\left(\mathrm{MoO}_{4}\right)_{2}\left(\mathrm{NH}_{4}\right)_{2} \mathrm{O} \cdot \mathrm{H}_{2} \mathrm{O}\left(\mathrm{NH}_{4}-\mathrm{ZM}\right)$ и его композиции с $\mathrm{SiO}_{2}\left(\mathrm{NH}_{4}-\mathrm{ZM} / \mathrm{SiO}_{2}\right)$ для перевода катионов $\mathrm{Nd}^{3+}$ в режиме «сорбция-кристаллизация» в фазу состава $\mathrm{Nd}_{2} \mathrm{Zr}_{3}\left(\mathrm{MoO}_{4}\right)_{9}$ (NZM), изоструктурную NZP-фазе. Показано, что композитный циркономолибдатный сорбент $\mathrm{NH}_{4}-\mathrm{ZM} / \mathrm{SiO}_{2}$ демонстрирует улучшенные эксплуатационные и сорбционные характеристики по сравнению с высокодисперсным слоистым циркономолибдатом, но не обладает достаточной механической прочностью. Это делает актуальным поиск способа получения циркономолибдатного сорбента с высокой механической прочностью и сорбционными свойствами, не уступающими достигнутым параметрам $\left(\mathrm{K}_{\mathrm{D}} \sim\right.$ не ниже $\left.10^{4} \mathrm{M} / / \Gamma\right)$.

Для укрупнения частиц сорбента и повышения их механической прочности применяются способы нанесения сорбционно-активных компонентов на носители, в качестве которых могут использоваться полые алюмосиликатные микросферы из летучих энергетических зол - ценосферы $[24,25]$. Ценосферы - полые сферы со стеклокристаллической оболочкой на основе алюмосиликатного стекла, содержащего включения кристаллических фаз кварца, муллита, кальцита и ферритовой шпинели [26, 27]. Кислотная обработка ценосфер определенного морфологического типа позволяет получить микросферический носитель с перфорированной макропористой оболочкой, в котором активный компонент может быть локализован как на внешней, так и внутренней поверхности [28]. Так, применение микросферического полого носителя на основе перфорированных ценосфер позволило решить проблему получения инженерной формы молибдофосфата аммония $\left(\mathrm{NH}_{4}\right)_{3}\left(\mathrm{PMo}_{12} \mathrm{O}_{40}\right) \cdot \mathrm{nH}_{2} \mathrm{O}$, являющигося высокоселективным сорбентом ${ }^{137} \mathrm{Cs}$ [29].

Целью данной работы стало получение микросферических сорбентов на основе композиций мезопористых циркономолибдатов и перфорированных ценосфер и изучение сорбционных 
свойств композитного сорбента в процессе извлечения катионов $\mathrm{Nd}^{3+}$ как имитатора трехвалентных актиноидов.

\section{Экспериментальная часть}

Pеагенты. Все вещества, которые использовались в данной работе, были марки ч.д.а.

Maтериальы. Для получения микросферического полого носителя использовали узкую фракцию ценосфер HMR - 0,08 + 0,071 мм, выделенную из концентрата ценосфер летучей золы от сжигания экибастузского угля, как описано в работе [30]. Данная фракция состоит из глобул трех морфологических типов - «ценосферы со сплошной оболочкой» (14 \%), «ценосферы с пористой оболочкой и гладкой поверхностью» $(84 \%)$ и «пенистые ценосферы» $(2 \%)$. Физические характеристики, макрокомпонентный и фазовый состав ценосфер узкой фракции представлены в табл. 1.

Получение микросферического носителя. $20 \mathrm{~cm}^{3}$ ценосфер помещали в полипропиленовый стакан и обрабатывали травильным раствором следующего состава: $\mathrm{NH}_{4} \mathrm{~F}-3,7$ г, $12 \mathrm{M} \mathrm{HCl}$ 10 мл, дистиллированная вода - до 100 мл. Время обработки - 15 мин, объемное соотношение твердая фаза : жидкость (т/ж) $1: 10$. По окончании обработки ценосферы разделяются на плавающий (неперфорированные ценосферы) и утонувший (перфорированный ценосферы) слои, которые выделяют методом декантации. Далее ценосферы промывают дистиллированной водой до отрицательной реакции на ионы $\mathrm{Cl}^{-}$с использованием реагента 0,1 моль-экв/л $\mathrm{AgNO}_{3}$. Оба слоя сушат отдельно в вентилируемой камере при $100-110{ }^{\circ} \mathrm{C}$. Для получения композитного сорбента используют перфорированные ценосферы с $\rho=0,38$ г/см³ и удельной поверхностью $0,5 \mathrm{~m}^{2} / \Gamma$ (рис. 1).

Синтез композиций иееносфер с ичиркономолибдатом. К 7 мл $1 \mathrm{M} \mathrm{ZrOCl}_{2}$ добавили 3,92 г $\mathrm{NH}_{4} \mathrm{HCO}_{3}$ (pH раствора 7-8) при перемешивании (раствор 1). В этих условиях сначала протекает гидролиз $\mathrm{ZrOCl}_{2}$ с образованием мутного раствора, который становится прозрачным при дальнейшем перемешивании за счет формирования растворимого комплексного соединения циркония с бикарбонат-анионами [31]. К 30 мл 0,1 M $\left(\mathrm{NH}_{4}\right)_{6} \mathrm{Mo}_{7} \mathrm{O}_{24}$ при перемешивании в течение 30 мин добавили 0,56 г цетилтетрадециламмоний бромида (СТАВ), выполняющего функцию

Таблица 1. Физические характеристики, макрокомпонентный и фазовый состав узкой фракции ценосфер HMR $-0,08+0,071 \mathrm{MM}$

Table 1. Physical characteristics, macrocomponent and phase composition of the HMR narrow cenosphere fraction $-0,08+0,071 \mathrm{~mm}$

\begin{tabular}{|c|c|c|c|c|c|c|c|c|}
\hline \multicolumn{3}{|c|}{ Физические характеристики } & \multicolumn{3}{|c|}{$\begin{array}{c}\text { Содержание макрокомпонентов, } \\
\text { мас. \% }\end{array}$} & \multicolumn{3}{|c|}{$\begin{array}{c}\text { Фазовый состав, } \\
\text { мас. } \%\end{array}$} \\
\hline 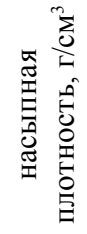 & 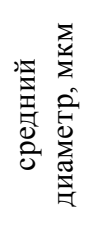 & 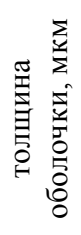 & $\mathrm{SiO}_{2}$ & $\mathrm{Al}_{2} \mathrm{O}_{3}$ & $\mathrm{Fe}_{2} \mathrm{O}_{3}$ & 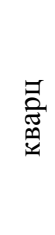 & 粪 & 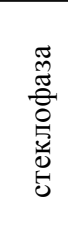 \\
\hline 0,42 & 76 & 4,1 & 59,9 & 34,9 & 1,1 & 1,5 & 34,7 & 63,5 \\
\hline
\end{tabular}



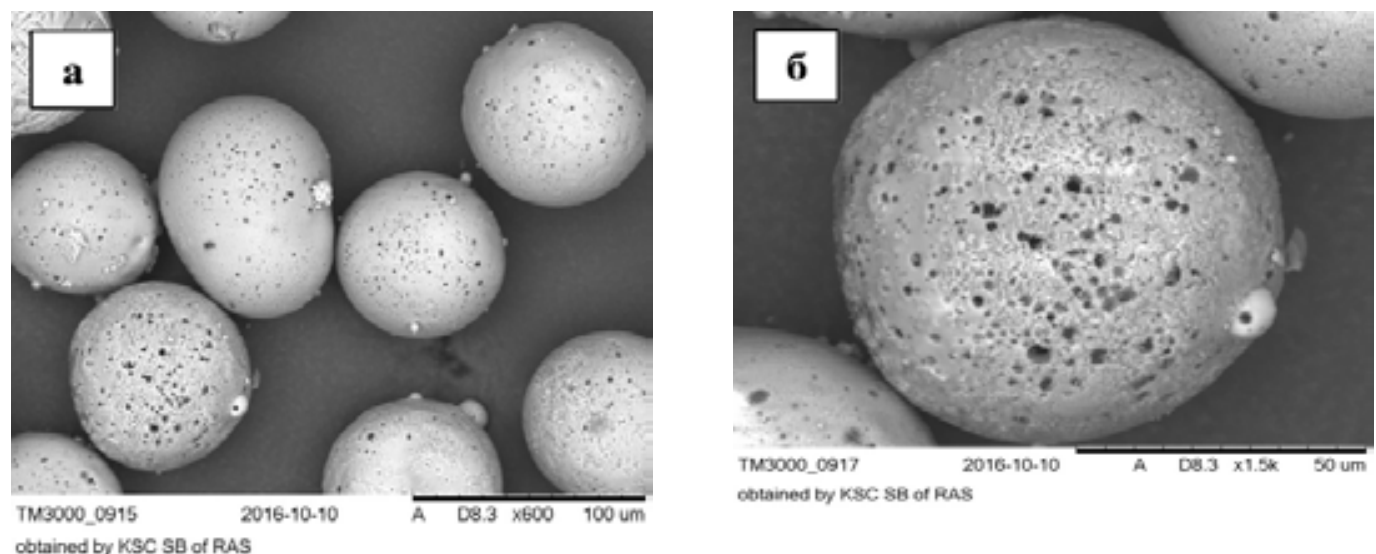

Рис. 1. РЭМ-снимки микросферического полого носителя

Fig. 1. SEM images of a microsphere hollow carrier

пороформирующего агента (раствор 2). Затем растворы 1 и 2 смешали с получением реакционной смеси с мольным отношением $\mathrm{Mo} / \mathrm{Zr}=3$, после чего добавили 5,7 г (15 мл) перфорированных полых микросфер. Реакционную смесь поместили в автоклав «BELUGA» (PremexAG, Швейцария) и подвергли вакуумированию в течение 30 мин с последующим выравниванием давления, в результате чего произошло заполнение раствором внутренних полостей перфорированных ценосфер. Далее синтез продолжали в течение 72 ч при температуре $150{ }^{\circ} \mathrm{C}$ при постоянном перемешивании со скоростью 70 об/мин.

По окончании синтеза полученный осадок отфильтровали, отмыли дистиллированной водой до отрицательной реакции на ионы $\mathrm{Cl}^{-}$и высушили при $110{ }^{\circ} \mathrm{C}$ в течение 4 ч. СТАВ удаляли путем прокаливания полученного образца при температуре $450{ }^{\circ} \mathrm{C}$ в течение 6 ч. Были выделены два продукта: дисперсный (0,34 г) (образец $\mathrm{mZM})$ и микросферический $(5,62$ г) (образец $\mathrm{mZM} / \mathrm{C})$.

Часть микросферического продукта $\mathrm{mZM} / \mathrm{C}$ была подвергнута взаимодействию в гидротермальных условиях с раствором $1 \mathrm{M} \mathrm{Na}_{2} \mathrm{MoO}_{4}$, подкисленного $3 \mathrm{M} \mathrm{HCl}$ до $\mathrm{pH}$ 1,5, при температуре $150{ }^{\circ} \mathrm{C}$ в течение 72 ч. Затем реакционную смесь охладили до комнатной температуры, полученный осадок отфильтровали, отмыли дистиллированной водой от ионов $\mathrm{Cl}^{\text {; }}$, а затем высушили при $50{ }^{\circ} \mathrm{C}$ в течение 20 ч. Отсутствие/наличие ионов $\mathrm{Cl}^{-}$контролировали с помощью 0,1 моль-экв/л $\mathrm{AgNO}_{3}$ (образец Мо-mZM/C).

Методика экспериментов по сорбции. Навески образцов сорбентов $(0,05 \pm 0,005$ г) помещали в пластиковые контейнеры и заливали 40 мл водного раствора, содержащего заданные концентрации неодима (от 0,5 до 50 мг/л). pH водных растворов, содержащих ионы неодима, составил 6-7. Растворы периодически взмучивали и выдерживали при комнатной температуре 24 ч. Время достижения равновесия было определено в ходе предварительных экспериментов.

Равновесные фазы разделяли фильтрованием, фильтрат анализировали на содержание катионов $\mathrm{Nd}^{3+}$ методом спектрофотометрии с применением органического реагента - Арсеназо I, который образует с ионом неодима интенсивно окрашенные и прочные хелаты [32]. 
Количество сорбированного неодима рассчитывали по разности концентраций в исходном и равновесном растворах по формуле (1)

$$
A=\frac{\left(C_{0}-C_{p}\right) \cdot V}{m}
$$

где $\mathrm{C}_{0}$ - исходная концентрация $\mathrm{Nd}^{3+}$ в растворе, мг/л; $\mathrm{C}_{\mathrm{P}}$ - равновесная концентрация $\mathrm{Nd}^{3+}$ в растворе, мг/л; $\mathrm{V}$ - объем исходного раствора, л; $\mathrm{m}$ - масса навески сорбента, г.

По экспериментальным данным построены изотермы сорбции неодима, которые были аппроксимированы уравнением Ленгмюра (2) [33]:

$$
A=\frac{a_{m} \cdot K_{L} \cdot C_{p}}{1+K_{L} \cdot C_{p}},
$$

где A - количество адсорбированного неодима на 1 г сорбента при равновесии, мг/г; $\mathrm{a}_{\mathrm{m}}$ - адсорбционная ёмкость сорбента при насыщении, $\mathrm{M \Gamma} / \Gamma ; \mathrm{K}_{\mathrm{L}}$ - константа уравнения Ленгмюра, л/ мг; $\mathrm{C}_{\mathrm{P}}-$ равновесная концентрация $\mathrm{Nd}^{3+}$ в растворе, мг/л.

Для проверки применимости модели к экспериментальным данным эмпирические уравнения Ленгмюра преобразовывали в линейную форму. Получение прямой линии в координатах $\mathrm{C}_{\text {равн. }} / \mathrm{A}-\mathrm{C}_{\text {равн. }}$ с коэффициентом корреляции $>0,97$ указывает на подчинение экспериментальной изотермы сорбции модели Ленгмюра.

На основании полученных данных рассчитывали такие параметры сорбции, как коэффициент распределения $\left(\mathrm{K}_{\mathrm{D}}\right.$, мл/Г), определенный в области микроконцентраций и рассчитанный из линейных изотерм при аппроксимации концентрации в растворе стремящейся к 0 , а также эффективность сорбции (Е, \%), используя уравнения (3) и (4) соответственно:

$$
\begin{aligned}
& K_{D}=\frac{C_{0}-C_{p}}{C_{p}} \cdot \frac{V}{m}, \\
& \mathrm{E}=\frac{\mathrm{C}_{0}-C_{p}}{C_{0}} \cdot 100 \% .
\end{aligned}
$$

Методы исследования. Фазовый состав образцов определяли методом порошкового рентгенофазового анализа с использованием подхода Ритвельда [34] и метода минимизации производной разности [35]. РФА-спектры записывали на дифрактометре PANalytical X'Pert PRO MPD (Нидерланды) с твердотельным детектором PIXcel и вторичным графитовым монохроматором для $\mathrm{Cu} \mathrm{K}_{\alpha}$ излучения.

Текстурные характеристики носителя, циркономолибдатов и микросферических композиций определяли на анализаторах удельной поверхности ASAP 2020MP-C (Micromeritics, CША) и Сорбтомер М (ИК СО РАН, Новосибирск) методом низкотемпературной адсорбции азота при 77 К. Удельную поверхность рассчитывали методом Брунауэра - Эммета - Теллера (БЭТ) по стандартной методике [36]. Кривые распределения пор по размерам получены, исходя из анализа адсорбционной ветви изотермы методом ВЈH (Barrett-Joyner-Halenda).

Электронно-микроскопические исследования образцов и определение элементного состава их поверхностей осуществляли с помощью настольного растрового электронного микроскопа (РЭМ) ТМ-3000 (Hitachi, Япония), оборудованного системой микроанализа Bruker, вклю-

$$
-316-
$$


чающей энергодисперсионный рентгеновский спектрометр (ЭДС) с детектором XFlash 430H и программным обеспечением QUANTAX 70. Рентгеноспектральный микроанализ (PCMA) проводили при ускоряющем напряжении 15 кВ в режиме отображения. Время накопления данных составило 10 мин.

Концентрацию катионов неодима в фильтратах сорбции определяли путем измерения оптической плотности на фотоэлектрическом фотометре КФК-3 (Россия) в кварцевых кюветах $(l=1$ см), рН растворов контролировали стеклянным электродом ЭСК-10601/7 на универсальном иономере Анион-4100 (ООО НПП «Инфраспак-Аналит», Россия).

\section{Результаты и обсуждение}

Дизайн микросферического полого носителя, получаемого в результате кислотного травления ценосфер, за счет наличия сквозных макропор в стенке размером 2-10 проводить модификацию как его внешней, так и внутренней поверхности (рис. 1). Составы реакционных сред и условия синтеза сорбционно-активных циркономолибдатов, предложенные ранее [22], оказались неприемлемыми для активации внутренней поверхности микросферического носителя ввиду быстрого осаждения осадка молибдата циркония в межсферном объеме. Для замедления процесса осадкообразования в реакционную среду был добавлен бикарбонат аммония, образующий комплексное соединение с катионами циркония [31], что позволило провести осаждение целевого продукта во внутреннем объеме ценосфер.

По данным РЭМ и РСМА микросферического продукта синтеза, циркономолибдат присутствует на внутренней и внешней поверхности носителя в виде пленки и отдельных агломератов, локализованных в открытых порах (рис. 2, 3). Для состава циркономолибдатного компонента композиции характерным является низкое мольное отношение $\mathrm{Mo} / \mathrm{Zr}$, не превышающее значения 0,4 , что почти на порядок ниже отношения $\mathrm{Mo} / \mathrm{Zr}$ в исходной реакционной смеси (табл. 2).

По данным метода низкотемпературной адсорбции азота нанесенный циркономолибдат представляет собой микромезопористый материал с удельной поверхностью около $200 \mathrm{M}^{2} / \Gamma$ и размером пор в интервале $10-40 \AA \mathrm{c}_{\max } \sim 15 \AA$ (рис. 4, табл. 2). Величина удельной поверхности композиции $\mathrm{mZM} / \mathrm{C}$ составила $15 \mathrm{~m}^{2} / \Gamma$, что соответствует степени нанесения циркономолибдата около $8 \%$.

Дополнительная гидротермальная обработка микросферической композиции $\mathrm{mZM} / \mathrm{C}$ в растворе молибдата натрия позволила повысить на порядок и выше отношение $\mathrm{Mo} / \mathrm{Zr}$ в продукте (табл. 2). Как видно на РЭМ-снимках, представленных на рис. 5 и 6, на поверхности микросфер и в межсферном пространстве присутствуют палочковидные образования на основе кристаллической фазы, неидентифицируемой методом РФА, которая по данным РСМА характеризуется повышенным содержанием молибдена (Mo/Zr $>30)$ (табл. 2, рис. 6a, б) и, скорее всего, является разновидностью микропористого гексагонального молибдата, образующегося в кислой среде из молибдата натрия (фаза $\mathrm{h}-\mathrm{Mo}_{\mathrm{x}} \mathrm{O}_{\mathrm{y}}$ ) [37]. Основная часть поверхности глобул покрыта пленкой молибдата циркония с $\mathrm{Mo} / \mathrm{Zr} \sim 4-8$, в которой $\mathrm{Zr}$ и Мо распределены неравномерно (табл. 2, рис. 66, г).

Сорбционные параметры индивидуального микромезопористого циркономолибдата $(\mathrm{mZM})$ и его композиций с ценосферами $(\mathrm{mZM} / \mathrm{C}$ и Mo-mZM/C), определенные из изотерм 


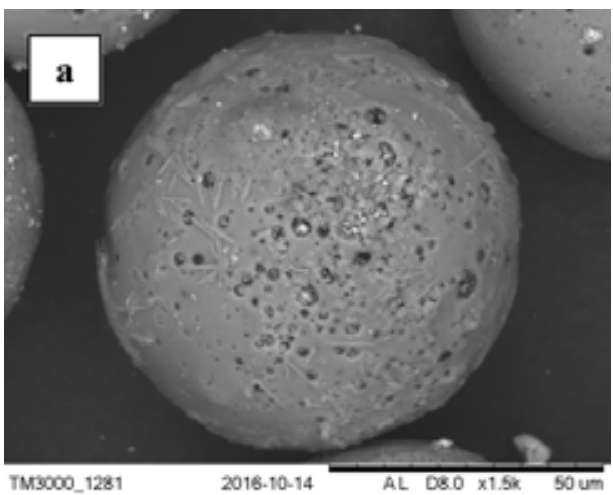

obtained by KSC SB of RAS

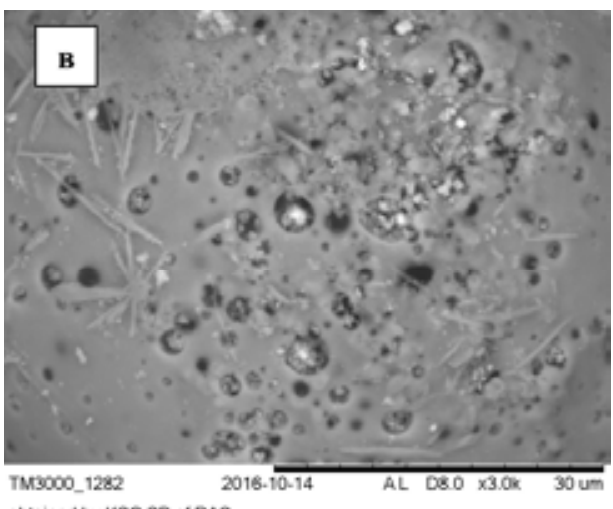

obtained by KSC SB of RAS

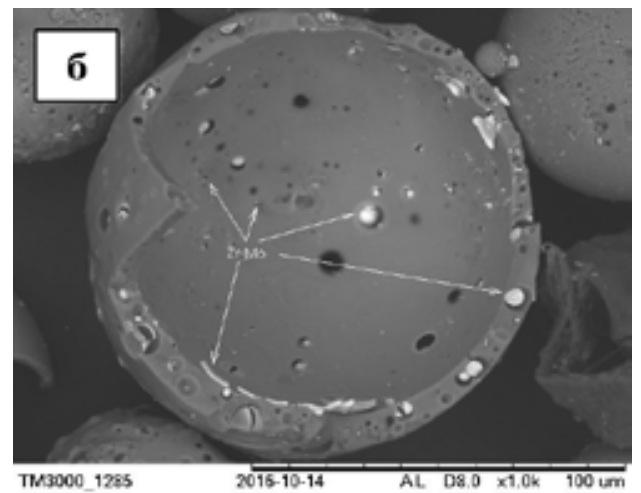

obtined by KSC S9 of RAS

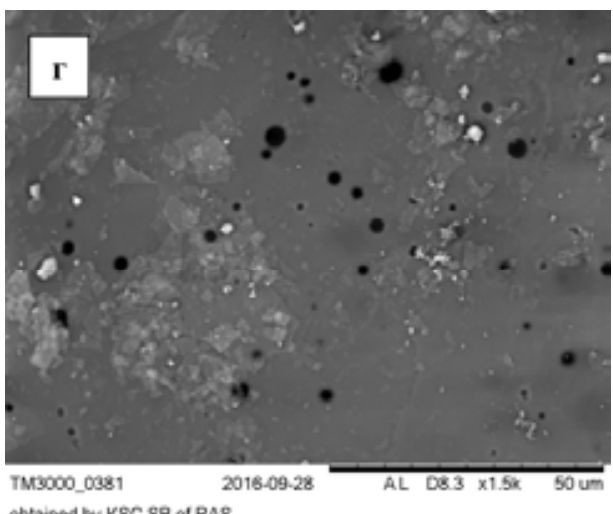

obtained by KSC s8 of RAS

Рис. 2. РЭМ-снимки микросферической композиции и отдельных ее фрагментов: а - глобула композиции; б - вид внутри; в - заполнение открытых пор; г - пленка на внутренней поверхности

Fig. 2. SEM images of the microsphere composition and its individual fragments: a - globule composition; $b$ inside view; $\mathrm{c}$ - filling of open pores; $\mathrm{d}$ - film on the inner surface

Таблица 2. Текстурные и сорбционные характеристики дисперсного циркономолибдата и микросферических композиций

Table 2. Texture and sorption characteristics of dispersed zirconium molybdate and microsphere compositions

\begin{tabular}{|c|c|c|c|c|c|c|}
\hline № & Образец & $(\mathrm{Mo} / \mathrm{Zr})_{\text {мол }}$ & $\mathrm{S}_{\text {уд }}, \mathrm{M}^{2} / \Gamma$ & $\mathrm{a}_{\mathrm{m}}, \mathrm{M} \Gamma / \Gamma$ & $\mathrm{K}_{\mathrm{D}}, \mathrm{Mл} / \Gamma$ & $\mathrm{E}, \%$ \\
\hline 1 & $\mathrm{mZM}$ & 0,4 & 200 & 10 & $0,7 \cdot 10^{4}$ & 89 \\
2 & $\mathrm{mZM} / \mathrm{C}$ & 0,4 & 15 & $6(75)^{*}$ & $0,2 \cdot 10^{4}$ & 67 \\
3 & $\mathrm{Mo-mZM/C}$ & 6,4 & 13 & 12 & $0,3 \cdot 10^{4}$ & 85 \\
\hline
\end{tabular}

* Расчет на 1 г активного компонента.

сорбции катионов $\mathrm{Nd}^{3+}$, приведены в табл. 2. На рис. 7 представлены изотермы сорбции $\mathrm{Nd}^{3+}$ и их линеаризованные формы для микросферических композиций.

Из данных табл. 2 видно, что индивидуальный циркономолибдат характеризуется относительно невысокой сорбционной емкостью в отношении $\mathrm{Nd}^{3+}$ (около $10 \mathrm{Mг} / \Gamma \mathrm{Nd}^{3+}$ ), что может быть связано с низким вхождением в структуру mZM атомов молибдена, являющихся источни- 

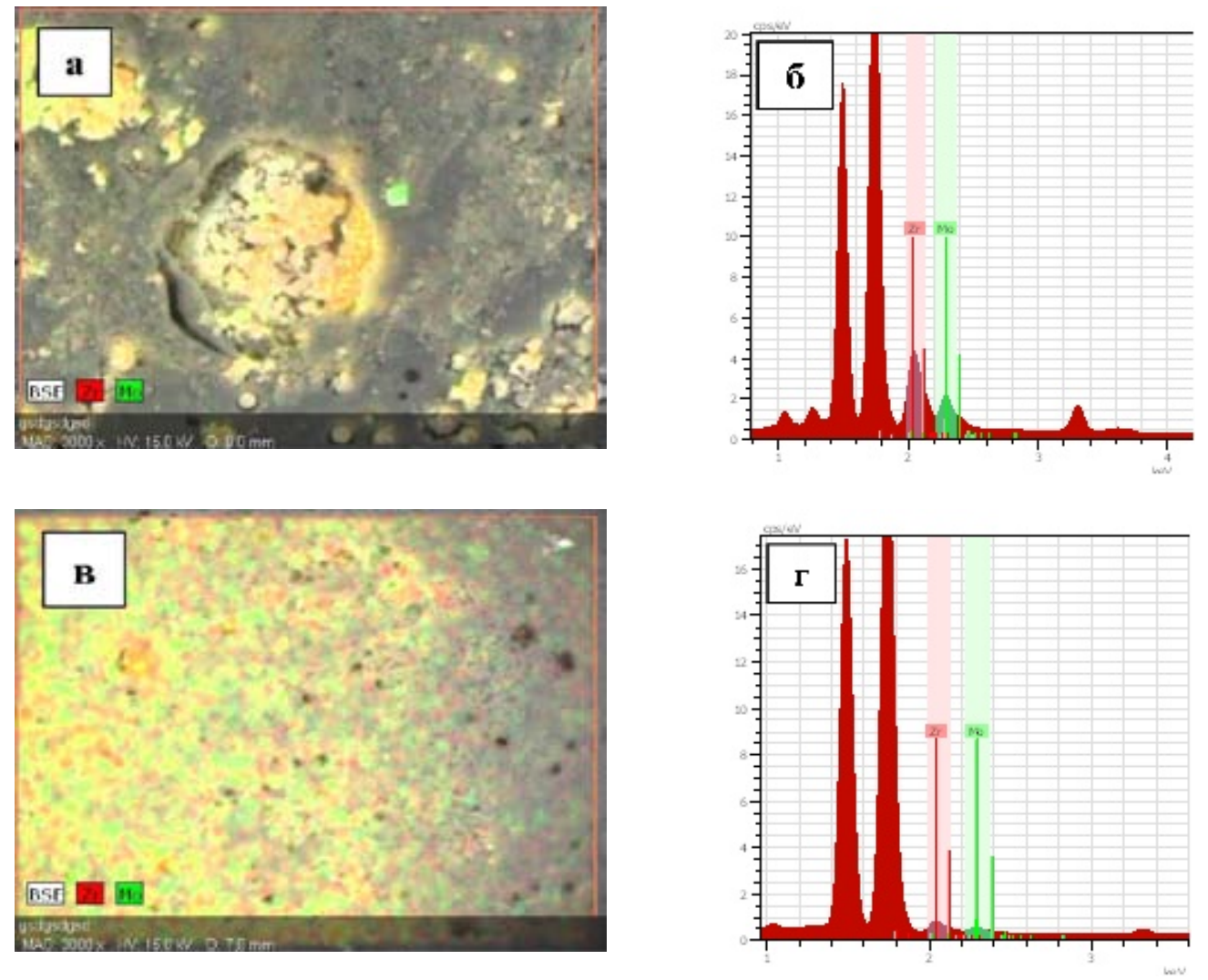

Рис. 3. Карты распределения (а, в) и профили концентраций (б, г) Zr и Мо по данным РЭМ в обратно отраженных электронах и РCMA для образца $\mathrm{mZM} / \mathrm{C}$ : a, б - внешняя поверхность; в, г - внутренняя поверхность

Fig. 3. Distribution maps (a, c) and concentration profiles (b, d) of $\mathrm{Zr}$ and Mo by the SEM data in back-scattered electrons and X-ray microanalysis for the sample mZM/C: $(a, b)$ outer surface; $(c, d)$ inner surface

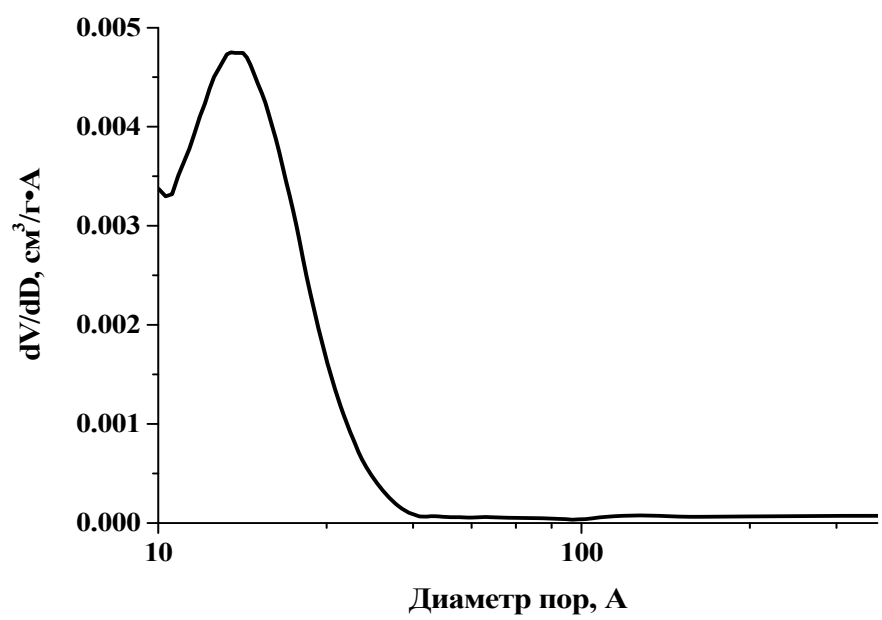

Рис. 4. Распределение пор по размерам для дисперсного циркономолибдата

Fig. 4. Pore size distribution for dispersed zirconium molybdate 

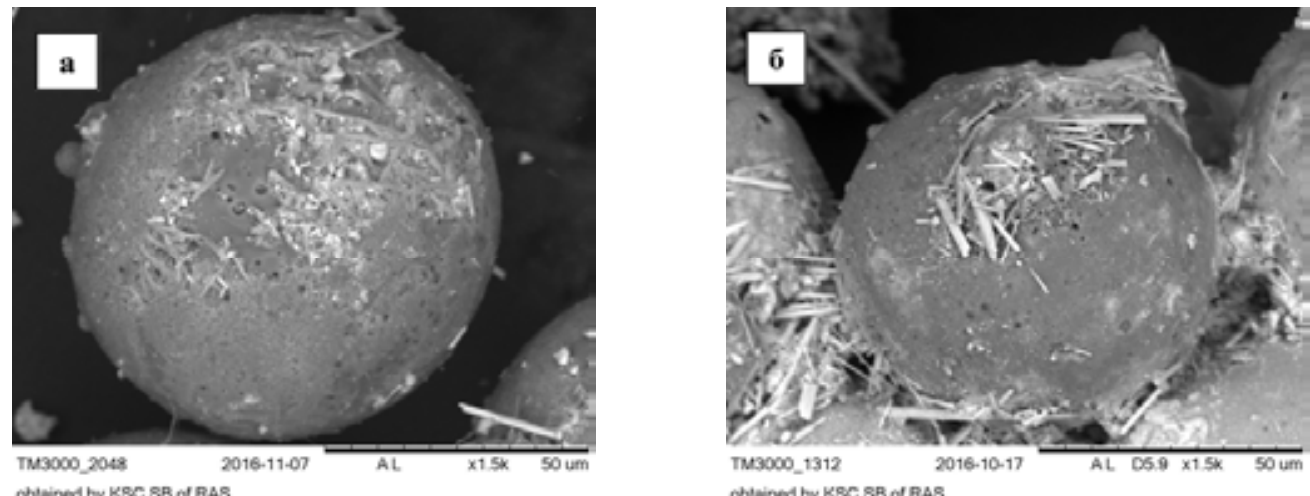

obtained by KSC SB of RAS

obleined by KSC SB of RAS

Рис. 5. РЭМ-снимки микросферической композиции Мо-mZM/C

Fig. 5. SEM images of the Mo-mZM/C microsphere composition
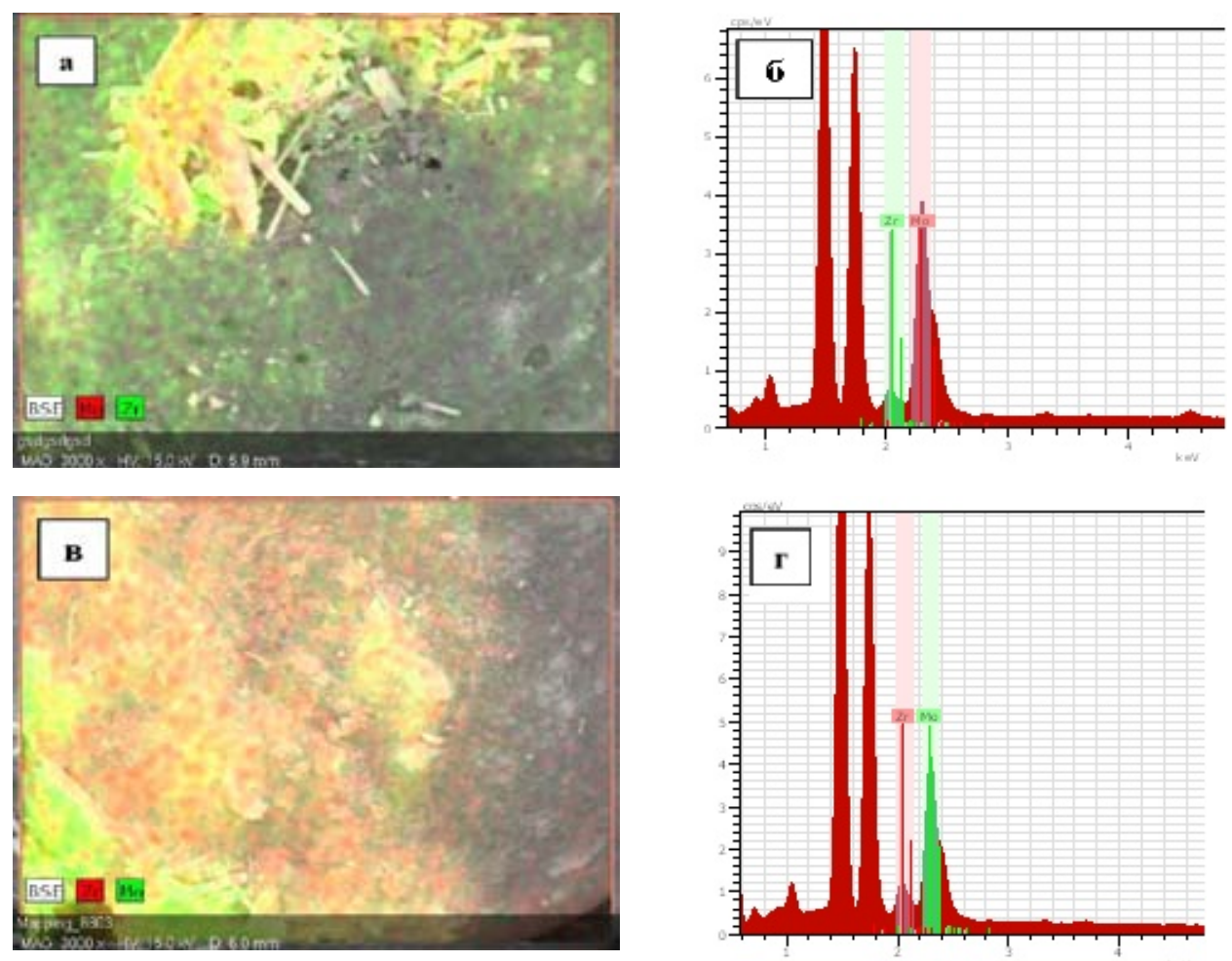

Рис. 6. Карты распределения (а, в) и профили концентраций (б, г) $\mathrm{Zr}$ и Мо по данным РЭМ в обратно отраженных электронах и РCMA для образца Mo-mZM/C: a, б - палочковидная фаза; в, г - пленка на внешней поверхности

Fig. 6. Distribution maps (a, c) and concentration profiles (b, d) of $\mathrm{Zr}$ and Mo by the SEM data in back-scattered electrons and X-ray microanalysis for the sample Mo-mZM/C: (a, b) rod-shaped phase; (c, d) film on the outer surface 

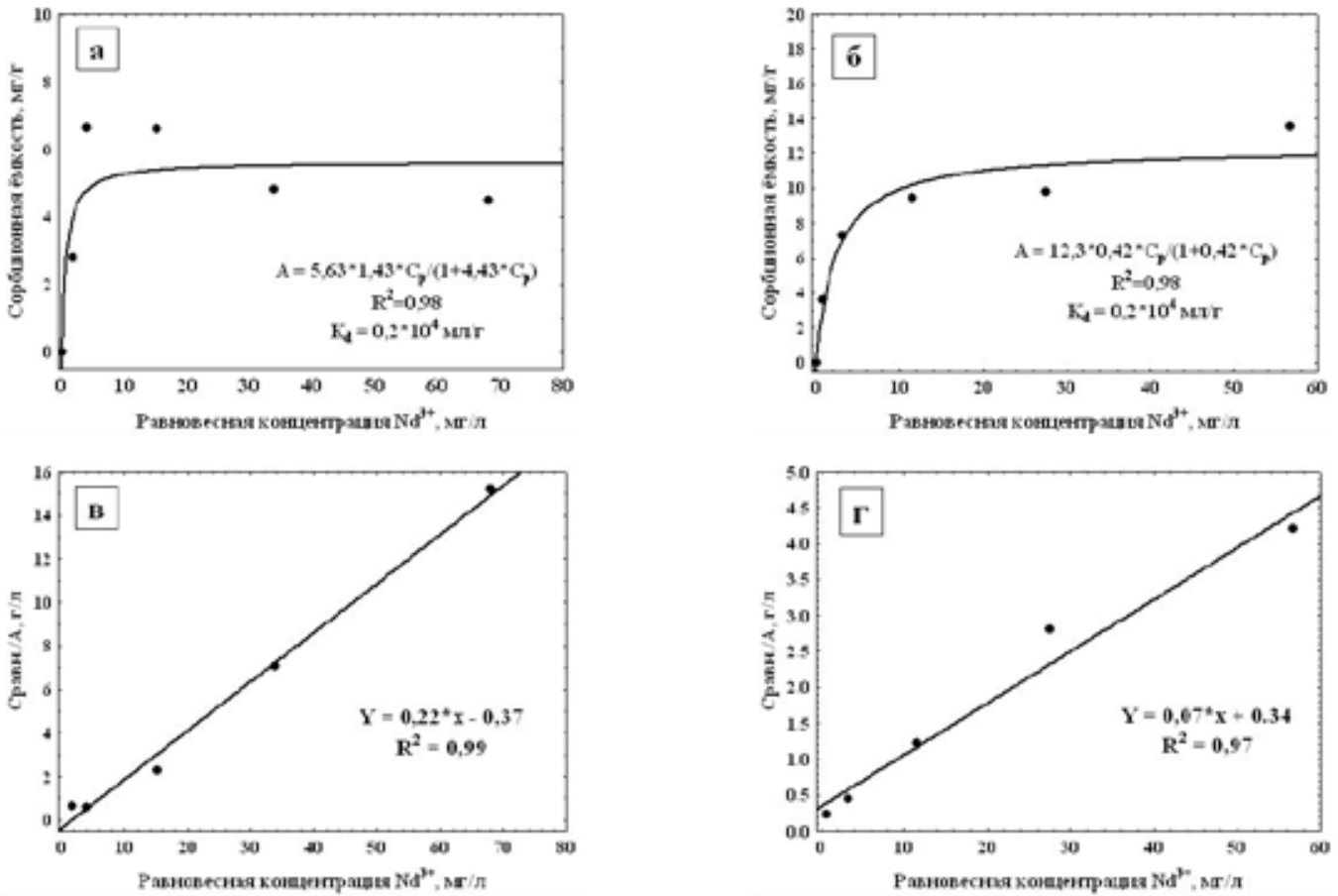

Рис. 7. Изотермы сорбции $\mathrm{Nd}^{3+}$ на композитных сорбентах (а, б) и их линеаризованные формы (в, г): $\mathrm{a}$, в $-\mathrm{mZM} / \mathrm{C}\left(\mathrm{a}_{\mathrm{m}}=5,6 \mathrm{Mг} / \Gamma\right) ;$ б, г - Mo-mZM/C ( $\mathrm{a}_{\mathrm{m}}=12,3$ мг/г) (точки - эксперимент, линии - модель Ленгмюра)

Fig. 7. Sorption isotherms of $\mathrm{Nd} 3+$ on composite sorbents $(\mathrm{a}, \mathrm{b})$ and their linearized forms $(\mathrm{c}, \mathrm{d}): \mathrm{a}, \mathrm{b}-\mathrm{mZM} / \mathrm{C}$ $\left(\mathrm{a}_{\mathrm{m}}=5.6 \mathrm{mg} / \mathrm{g}\right) ; \mathrm{b}, \mathrm{d}-$ Mo-mZM/C $\left(\mathrm{a}_{\mathrm{m}}=12.3 \mathrm{mg} / \mathrm{g}\right)$ (points - experiment, lines - Langmuir model)

ком кислых сорбционно-активных -ОН групп, и/или низкой доступностью сорбционных центров в объемном материале. Тонкослойное распределение активного компонента при степени нанесения около 8 \% способствует повышению его удельной емкости в несколько раз (табл. 2). Увеличение соотношения $\mathrm{Mo} / \mathrm{Zr}$ путем взаимодействия композиции с $\mathrm{Na}_{2} \mathrm{MoO}_{4}$ привело к ожидаемому повышению емкости композиции (табл. 2). Предположительно, увеличение числа сорбционных центров происходит за счет как дополнительного связывания молибдатных групп на поверхности мезопористого циркономолибдата, так и формирования фазы h-Mo $\mathrm{Mo}_{\mathrm{y}}$, способной к ионному обмену [37]. Индивидуальный циркономолибдат и обе композиции характеризуются высокими коэффициентами распределения (до $10^{4}$ мл/г), в то время как среди композиций эффективность сорбции выше в случае образца с повышенным содержанием молибдена (табл. 2).

\section{Выводы}

Впервые получены микросферические циркономолибдатные сорбенты путем нанесения микромезопористых циркономолибдатов $\left(\mathrm{D}_{\max } \sim 15 \AA\right)$ на макропористый микросферический носитель ( $\left.\mathrm{D}_{\text {пор }} \sim 2-10 \mu \mathrm{m}\right)$ на основе ценосфер определенного состава и морфологии, позволяющие извлекать из водных сред катионы неодима как имитатора трехвалентных актиноидов с коэффициентом распределения до $10^{4}$ мл/г и эффективностью сорбции до 85 \%. Установлено, 
что достижение высоких значений коэффициента распределения и эффективности сорбции $\mathrm{Nd}^{3+}$ обеспечивается тонкослойным нанесением циркономолибдата на носитель и повышенным содержанием Мо в его составе $(\mathrm{Mo} / \mathrm{Zr}>4)$, в том числе за счет формирования в процессе синтеза фазы оксида молибдена, способной к ионному обмену. Вместе с тем однозначные выводы о перспективности материалов для извлечения и иммобилизации радиоактивных РЗЭ и ТПЭ будут сделаны лишь в результате более детальных исследований сорбционных характеристик, учитывающих влияние $\mathrm{pH}$ и присутствие посторонних ионов на емкость полученных сорбентов.

Работа выполнена за сиет средств Федерального бюджета на реализацию проекта № V.45.3.1 в рамках программы ФНИ ГАН на 2013-2016 г2. Авторы выражают благодарность сотрудникам ИХХТ СО РАН Л.А. Соловьеву за проведение количественного рентгенофазового анализа, В.В. Юмачеву и О. Фетисовой за определение текстурных характеристик сорбентов.

\section{Список литературы}

1. URL: http://rareearth.ru/ru/news/20160729/02337.html

2. Adachi G., Imanaka N., Tamura S. Research trends in rare earths: A preliminary analysis. Journal of Rare Earths. 2010. Vol. 28, P. 843-846.

3. Veliscek-Carolan J., Hanley T.L., Luca V. Zirconium organophosphonates as high capacity, selective lanthanide sorbents. Separation and Purification Technology 2014. Vol. 129, P. 150-158.

4. Yoon S.-J., Helmke P.A., Amonette J.E., Bleam W.F. X-ray absorption and magnetic studies of trivalent lanthanide ions sorbed on pristine and phosphate-modified boehmite surfaces. Langmuir 2002. Vol. 18, P. 10128-10136.

5. Minimization of radioactive waste from nuclear power plants and the back end of the nuclear fuel cycle: Technical Report Series No. 377. International Atomic Energy Agency. Vienna : IAEA, 1995. 84 p.

6. Donald I.W., Metcalfe R.N., Taylor R.N.J. The immobilization of high level radioactive waste using ceramics and glasses (Review). Journal of Materials Science 1997. Vol. 32, P. 5851-5887.

7. Dosch R.G. Ceramics from ion exchangers: an approach to nuclear waste solidification. Journal of American Nuclear Society 1975. Vol. 2, P. 355-357.

8. Vereshchagina T.A., Vereshchagin S.N., Shishkina N.N., Solovyov L.A., Vasilieva N.G., Anshits A.G. Microsphere zeolite materials derived from coal fly ash cenospheres as precursors to minerallike aluminosilicate hosts for ${ }^{135,137} \mathrm{Cs}$ and ${ }^{90} \mathrm{Sr}$. Journal of Nuclear Materials 2013. Vol. 437, P. 11-18.

9. Luca V., Griffith C.S., Drabarek E., Chronis H. Tungsten bronze-based nuclear waste form ceramics. Part 1. Conversion of microporous tungstates to leach resistant ceramics. Journal of Nuclear Materials 2006. Vol. 358, P. 139-150.

10. Pavel C.C., Walter M., Poml P., Bouexiere D., Popa K. Contrasting immobilization behavior of $\mathrm{Cs}^{+}$and $\mathrm{Sr}^{2+}$ cations in a titanosilicate matrix. Journal of Materials Chemistry 2011. Vol. 21, P. 3831-3837.

11. Cappelletti P., Rapisardo G., Gennaro B., Colella A., Langella A., Graziano S.F., Bish D.L., Gennaro M. Immobilization of $\mathrm{Cs}$ and $\mathrm{Sr}$ in aluminosilicate matrices derived from natural zeolites. Journal of Nuclear Materials 2011. Vol. 414, P. 451-457. 
12. Vereshchagina T.A., Anshits N.N., Sharonova O.V., Vasilieva N.G., Vereshchagin S.N., Shishkina N.N., Fomenko E.V., Anshits A.G. Polyfunctional Microspherical Materials for Long-Term Burial of Liquid Radioactive Wastes. Glass Physics and Chemistry 2008. Vol. 34, P. 547-558.

13. Pichot E., Dacheux N., Brandel V., Groupe M.G. Investigation of ${ }^{137} \mathrm{Cs}^{+},{ }^{85} \mathrm{Sr}^{2+}$ and ${ }^{241} \mathrm{Am}^{3+}$ ion exchange on thorium phosphate hydrogenphosphate and their immobilization in the thorium phosphate diphosphate. New Journal of Chemistry 2000. Vol. 24, P. 1017-1023.

14. Vasilieva N.G., Anshits N.N., Sharonova O.M., Burdin M.V., Anshits A.G. Immobilization of Cesium and Strontium Radionuclides in Framework Aluminosilicates with the Use of Porous GlassCeramic Matrices Based on Coal Fly Ash Cenospheres. Glass Physics and Chemistry 2005. Vol. 31, P. 637-647.

15. Konovalov E.E., Starkov O.V., Glagovskii E.M., Myshkovskii M.P., Kuprin A.V., Pelevin L.P., Gudkov L.S., Nardova A.K. Immobilization of silica gel fixed cesium and strontium into mineral-like matrices in the SHS mode. Radiochemistry 2002. Vol. 44, P. 420-422.

16. Trachenko K. Topical Review. Understanding resistance to amorphization by radiation damage. Journal of Physics Condensed Matter 2004. Vol. 16, P. 1491-1515.

17. Waste forms technology and performance: Final report. Washington D.C.: The National Academies Press, 2011. 308 p.

18. Hirose Y., Fukasawa T., Agraval D.K., Scheetz B.E., Nageswaran R., Curtis J.A., Limaye S.Y. An alternative process to immobilize intermediate wastes from LWR fuel reprocessing. Proc. Int. Conf. Waste Management (WM'99), February 28 - March 4, 1999. Tucson, Arizona, USA. URL: http://www.wmsym.org/archives/1999/60/60-7.pdf.

19. Orlova A.I., Orlova V.A., Orlova M.P., Bykov D.M., Stefanovskii S.V., Stefanovskaya O.I., Nikonov B.S. The crystal-chemical principle in designing mineral-like phosphate ceramics for immobilization of radioactive waste. Radiochemistry 2006. Vol. 48(4), P. 330-339.

20. Luca V., Bertram W., Widjaja J., Mitchell D.R.G., Griffith C.S., Drabarek E. Synthesis of mesoporous zirconium titanates using alkycarboxylate surfactants and their transformation to dense ceramics. Microporous Mesoporous Materials 2007. Vol. 103, P. 123-133.

21. Veliscek-Carolan J., Hanley T.L., Luca V. Zirconium organophosphonates as high capacity, selective lanthanide sorbents. Separation and Purification Technology 2014. Vol. 129, P. $150-158$.

22. Vereshchagina T.A., Fomenko E.V., Vasilieva N.G., Solovyov L.A., Vereshchagin S.N., Bazarova Zh.G., Anshits A.G. A novel layered zirconium molybdate as a precursor to a ceramic zirconomolybdate host for lanthanide bearing radioactive waste. Journal of Materials Chemistry 2011. Vol. 21, P. 12001-12007.

23. Кутихина Е.А., Верещагина Т.А. Композитные циркономолибдатные сорбенты для иммобилизации катионов f-металлов (III) в минералоподобной матрице. Журнал Сибирского федерального университета. Химия 2016. Т. 9. № 2, С. 159-170. [Kutikhina E.A., Vereshchagina T.A. Composite zirconomolybdates sorbents for extraction of f-metal cations from liquid radioactive waste and their immobilization in a mineral-form. Journal of Siberian Federal University. Chemistry 2016. Vol. 9(2), P. 159-170. (In Russ.)]

24. Danilin L.D., Drozhzhin V.S. Inorganic Sorbents Based on Modified Microspheres for Treatment of Liquid Radioactive Waste. Radiochemistry. 2007. Vol. 49(3), P. 319-322. 
25. Vereshchagina T.A., Anshits N.N., Sharonova O.M., Vasil'eva N.G., Vereshchagin S.N., Shishkina N.N., Fomenko E.V., Anshits A.G. Polyfunctional Microspherical Materials for Long-Term Disposal of Liquid Radioactive Wastes. Glass Physics and Chemistry 2008. Vol. 34(5), P. 547-558.

26. Fomenko E.V., Anshits N.N., Solovyov L.A., Mikhailova O.A., Anshits A.G. Compositions and morphology of fly ash cenospheres produced from the combustion of Kuznetsk coal. Energy \& Fuels 2015. Vol. 29, P. 5390-5403.

27. Anshits N.N., Vereshchagina T.A., Bayukov O.A., Salanov A.N., Anshits A.G. The nature of nanoparticles of crystalline phases in cenospheres and morphology of their shells. Glass Physics and Chemistry 2005. Vol. 31(3), P. 306-315.

28. Pankova M.V., Fomenko E.V., Anshits N.N., Vereshchagina T.A., Anshits A.G. Microspherical supports and sorbents for processes in aggressive media. Chemistry for sustainable development 2010. Vol. 18(5), P. 593-601.

29. Tranter T.J., Vereshchagina T.A., Utgikar V. An inorganic microsphere composite for the selective removal of ${ }^{137} \mathrm{Cesium}$ from acidic nuclear waste solutions. 1: Equilibrium capacity and kinetic properties of the sorbent. Solvent Extraction and Ion Exchange 2009. Vol. 27, P. 199-218.

30. Михайлова О.А., Роговенко Е.С., Фоменко Е.В. Состав и строение оболочки глобул узких фракций немагнитных неперфорированных ценосфер низкой насыпной плотности. Современные проблемы науки и образования 2015. № 1-1. [Mikhailova O.A., Rogovenko E.S., Fomenko E.V. Composition and structure of shell globules of narrow fractions of non-magnetic, nonperforated cenospheres of low bulk density. Modern Problems of Science and Education 2015. Vol. 1-1. (In Russ.)]. URL: https://www.science-education.ru/ru/article/view?id=19630.

31. Sarkar A., Pramanik S., Achariya A., Pramanik P. A novel sol-gel synthesis of mesoporous $\mathrm{ZrO}_{2}-\mathrm{MoO}_{3} / \mathrm{WO}_{3}$ mixed oxides. Microporous and mesoporous materials 2008. Vol. 115, P. 426-431.

32. Гатиятуллина Л.Я., Борейко Н.П., Ахметова Т.И. Фотоколориметрическое определение неодима в каучуках и сточной воде. Заводская лаборатория. Диагностика материалов 2012. T. 78(4), C. 13-16. [Gatiyatullina L.Ya., Boreiko N.P., Akhmetova T.I. Photocolorimetric determination of neodymium in rubbers and wastewater. Factory laboratory. Diagnostics of materials 2012. Vol. 78(4), P. 13-16. (In Russ.)].

33. Грег С., Синг К. Адсорбция, удельная поверхность, пористость. Пер. с англ. 2-е изд. М.: Мир, 1984. 306 с., ил. [Greg S., Singh K. Adsorption, surface area, porosity. Per. from English. 2nd izd. M.: Mir, 1984. 306 p., Ill. (In Russ.)].

34. Reitveld H. A profile refinement method for nuclear and magnetic structures. Journal of Applied Crystallography 1969. Vol. 2, P. 65-71.

35. Solovyov L.A. Full-profile refinement by derivative difference minimization. Journal of Applied Crystallography 2004. Vol. 37, P. 743-749.

36. ISO 9277:2010-09 (E). Determination of the specific surface area of solids by gas adsorptionBET method.

37. Whittingham M.S., Guo J.-D., Chen R., Chirayil T., Janauer G., Zavalij P. The hydrothermal synthesis of new oxide materials. Solid State Ionics 1995. Vol. 75, P. 257-268. 